
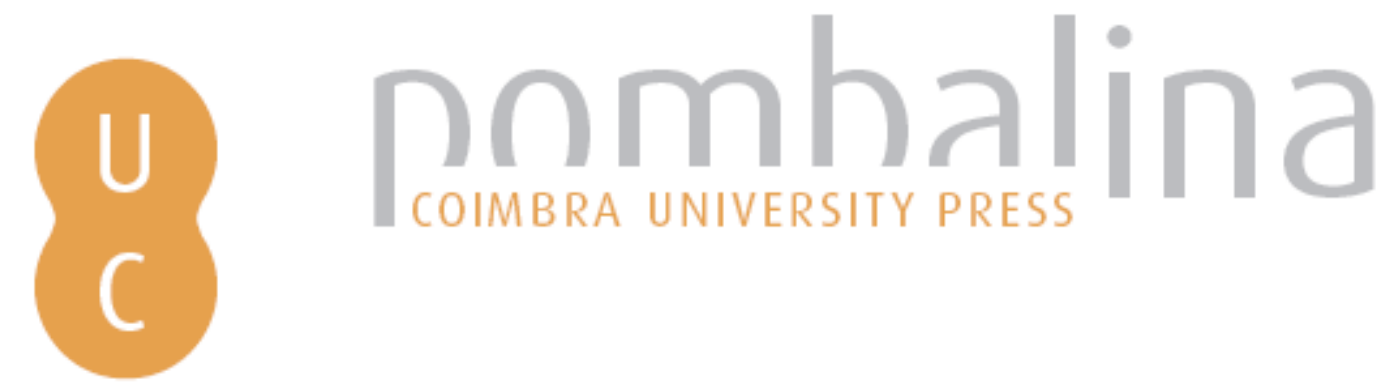

\title{
Propaganda ideológica en el teatro neolatino y romance de los colegios de jesuitas en el Siglo de Oro español
}
Autor(es):
Menéndez Peláez, Jesús
Publicado por: Imprensa da Universidade de Coimbra
URL
persistente:
URI:http://hdl.handle.net/10316.2/32350
DOI:
DOI:http://dx.doi.org/10.14195/978-989-26-0482-4_4
Accessed : $\quad$ 26-Apr-2023 15:53:38

A navegação consulta e descarregamento dos títulos inseridos nas Bibliotecas Digitais UC Digitalis, UC Pombalina e UC Impactum, pressupõem a aceitação plena e sem reservas dos Termos e Condições de Uso destas Bibliotecas Digitais, disponíveis em https://digitalis.uc.pt/pt-pt/termos.

Conforme exposto nos referidos Termos e Condições de Uso, o descarregamento de títulos de acesso restrito requer uma licença válida de autorização devendo o utilizador aceder ao(s) documento(s) a partir de um endereço de IP da instituição detentora da supramencionada licença.

Ao utilizador é apenas permitido o descarregamento para uso pessoal, pelo que o emprego do(s) título(s) descarregado(s) para outro fim, designadamente comercial, carece de autorização do respetivo autor ou editor da obra.

Na medida em que todas as obras da UC Digitalis se encontram protegidas pelo Código do Direito de Autor e Direitos Conexos e demais legislação aplicável, toda a cópia, parcial ou total, deste documento, nos casos em que é legalmente admitida, deverá conter ou fazer-se acompanhar por este aviso.

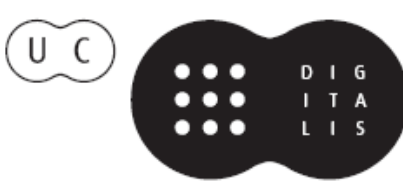


Sebastiāo Tavares de Pinho

Coordenação

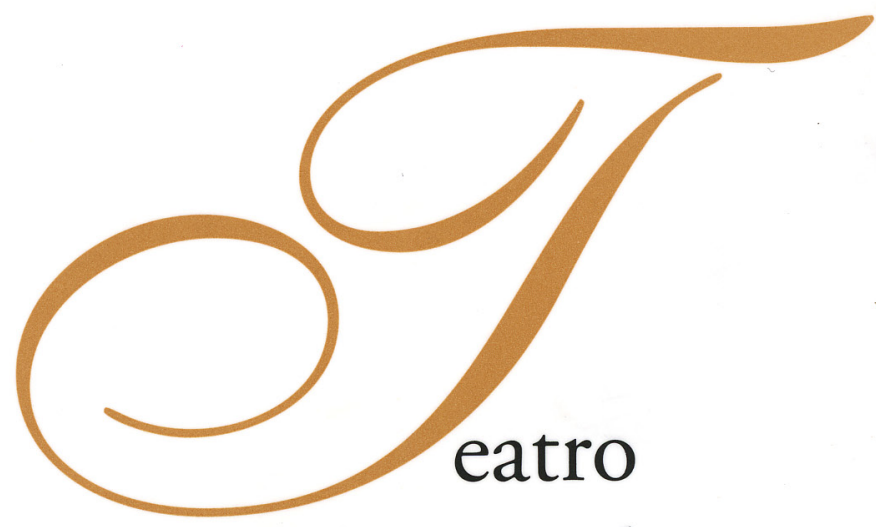

Neolatino em Portugal

no Contexto da Europa

450 Anos

de Diogo de Teive

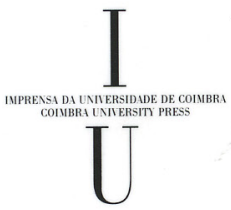

- COIMBRA 2006 
(Página deixada propositadamente em branco) 
C

U

M

E

$\mathrm{N}$

T

0

S

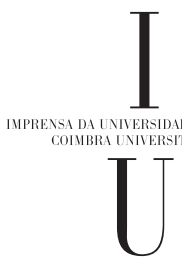




\section{COORDENAÇÃO EDITORIAL}

Imprensa da Universidade de Coimbra

URL: http//www.imp.uc.pt

\section{CONCEPÇÃo GRÁFICA}

António Barros

PRÉ-IMPRESSÃo

António Resende

Imprensa da Universidade de Coimbra

EXECUÇÃo GRÁFICA

SerSilito - Maia

ISBN

$972-8704-75-5$

DEPÓSITO LEGAL

(C) Junho 2006, Imprensa da Universidade de Coimbra

OBRA PUBLICADA COM O FINANCIAMENTO DE:

Centro de Estudos Clássicos e Humanísticos

FCT Fundação para a Ciência e a Tecnologia

MINISTÉRIO DA CIÊNCIA, TECNOLOGIA E ENSINO SUPERIOR Portugal

OBRA PUBLICADA COM O APOIO DE:

FCT: Fundação para a Ciência e Tecnologia • Ministério da Ciência e do Ensino Superior Apoio do Programa Operacional para a Ciência, Tecnologia, Inovação do III Quadro Comunitário de Apoio 
O TEATRO NeOlatino EM PORTUGal NO CONTEXTO DA EUROPA

450 AnOs DE DIOGO DE TEIVE 
(Página deixada propositadamente em branco) 
Jesús Menéndez Peláez

Universidad de Oviedo

PROPAGANDA IDEOLÓGICA EN EL TEATRO NEOLATINO Y ROMANCE

DE LOS COLEgIOS DE JESUITAS EN EL SIGLO DE ORO ESPAÑOL

\section{El contexto de la investigación}

Desde 1978, en la Universidad de Oviedo, se viene trabajando, bajo mi dirección, en un amplio proyecto de investigación sobre Los Jesuitas y el teatro en el Siglo de Oro ${ }^{(1)}$; en este proyecto colaboran también las Universidades de Navarra y Toulouse con el asesoramiento, respectivo, de los profesores Ignacio Arellano y Marc Vitse.

La investigación tiene programadas varias fases:

$1^{a}$ Compilación, a través de microfilms o microfichas de todos los manuscritos que contienen las obras dramáticas de este teatro jesuítico que custodian la Biblioteca Real de la Historia, la Biblioteca Nacional de Madrid y las bibliotecas privadas de distintos colegios de la Compañía de Jesús, repartidos por la geografía nacional. Este objetivo está ya cumplido.

$2^{a}$ Descripción, lo más completa posible, de los manuscritos que contienen las obras del teatro jesuítico, con el fin de elaborar un catálogo o inventario real, lo más exhaustivo, de las obras actualmente existentes de

(1) Un avance de este proyecto fue ya publicado: Jesús MENÉNDEZ PELÁEZ, Los jesuitas y el Teatro en el Siglo de Oro, Oviedo, Universidad, 1995. También puede verse una síntesis del teatro latino-castellano, universitario y de colegio, en IDEM, "El teatro escolar latino-castellano en el siglo XVI", en Javier HUERTA CALVO (Dir.), Historia del Teatro Español, Madrid, Gredos, vol. I, 2003, pp. 581-608; más recientemente un estado de la cuestión en IDEM, "Estudios sobre el teatro jesuítico español en el Siglo de Oro: Status quaestionis», Ínsula, 695, 2004, pp. 2-5. 
este teatro jesuítico. Los resultados han sido publicados en la revista Archivum [Universidad de Oviedo], LIV-LV (2004-2005) 421-563.

$3^{\text {a }}$ Distribución y clasificación de las obras por subgéneros dramáticos tomando como criterios aspectos prioritariamente religiosos, ya sea de naturaleza litúrgica o ya de intertextualidad con las Sagradas Escrituras, pues la mayor parte de este teatro se representaba siguiendo el curso del calendario del ritual cristiano: hagiografías (fiestas de los santos), autos sacramentales (Corpus), Navidad, Semana Santa, de inspiración bíblica (Nuevo y Antiguo Testamento), cristianización de elementos paganos y de circunstancias.

$4^{a}$ Elaboración de la nómina de aquellos dramaturgos más representativos del teatro jesú́tico en un intento de ofrecer los datos pertinentes de su biografía. No obstante, este apartado ofrece problemas de atribución, ya que muchas de las obras del teatro jesuítico no llevan atribución de autor, sino tan solo el marbete "Por uno de la Compañía", expresión que quizá derive del voto de humildad de los dramaturgos; de esta manera, se evitaba cualquier tipo de protagonismo que pudiera poner en peligro esa virtud. Es una praxis bastante habitual en los hijos de san Ignacio hasta épocas recientes; en ocasiones un anónimo y posterior amanuense - la caligrafía lo ratifica - escribe el nombre del dramaturgo a quien ese amanuense o lector avisado atribuye la obra, lo que facilita, con ciertos riesgos, el problema de la autoría.

$5^{\text {a }}$ Edición-transcripción individualizada de cada una de las obras, un proyecto en el que están implicados alumnos de los distintos ciclos de la enseñanza reglada de nuestras respectivas universidades.

$6^{\text {a }}$ Creación de una página web destinada a recoger trabajos y ediciones del teatro jesuítico español. Al tratarse de obras, por lo general muy extensas, y siendo un teatro, cuyos textos por el momento no forman parte del canon literario, su publicación a través de la imprenta quizá pueda resultar difícil por su elevado coste; sin embargo, resulta muy sencillo difundir, con una finalidad divulgativa, estas ediciones a través de Internet. El servicio que con ello se hace a la investigación humanística resulta patente. 
$7^{a}$ Uno de los pioneros en el estudio del teatro jesuítico español fue, junto con Justo García Soriano(2), el P. Félix G. de Olmedo, especialista de reconocido prestigio en la oratoria sagrada del Siglo de Oro, quien dejó publicado tan solo una mínima parte de lo que tenía preparado; el Colegio de san Estanislao de Kostka en Salamanca custodia un ingente material inédito sobre la historia de la predicación medieval y del Siglo de Oro, algunos de cuyos trabajos ya estaban terminados para enviar a la imprenta. Junto con la oratoria sagrada, el teatro jesuítico fue otra de sus preocupaciones, dejando igualmente trabajos completos para la imprenta. El P. Olmedo fue un entusiasta admirador del P. Juan Bonifacio que emerge en la cultura del siglo XVI como pedagogo y como dramaturgo y que es el autor del conocido Códice de Villagarcía, una de las compilaciones más importantes y mejor conocidas, principalmente a través de los comentarios analíticos de García Soriano; la personalidad de este pedagogo y dramaturgo nos es bien conocida gracias a los estudios del P. Olmedo(3), quien tenía también preparados unos «Breves apuntes para Historia del teatro en los antiguos colegios de la Compañía", así como la trascripción de varias obras de teatro de Hernando de Ávila, Salvador de León, Pedro de Salas y otros; también había concluido una edición-trascripción completa, sin duda la primera, de la Tragedia de san Hermenegildo; en su archivo se conserva una carta — fechada el 26 de diciembre de 1935 - que le remite desde Roma el P. Dionisio Fernández, a quien el P. Olmedo había consultado aspectos muy concretos de estas obras; esto quiere decir que el P. Olmedo, antes de la guerra civil, ya tenía ultimada las ediciones del "Códice de Villagarcía” y de la Tragedia de san Hermenegildo, así como otras obras de los autores referidos. La falta de sensibilidad hacia esta temática literaria, que caracterizó durante mucho tiempo a la universidad española, quizá haya sido

(2) Justo GARCÍA SORIANO, El teatro universitario y bumanístico en España. Estudios sobre el origen de nuestro arte dramático; con documentos, textos inéditos y un catálogo de antiguas comedias escolares, Toledo, 1945.

(3) Félix G. OLMEDO, Juan Bonifacio (1538-1606) y la cultura literaria del Siglo de Oro, Santander, Publicaciones de la Sociedad de Menéndez Pelayo, 1938. 
la causa de que aquellos materiales no hayan visto la luz de la imprenta. Tan solo dejó publicadas algunas consideraciones sobre la relación entre determinadas obras del teatro jesuítico y La vida es sueño de Calderón de la Barca(4) $^{(4)}$ No obstante, su obra está ahí y en breve se irá dando a conocer, ya que fue uno de los pioneros en los estudios sobre el teatro jesuítico en la España del Siglo de Oro. Con el objeto de hacer justicia a las investigaciones realizadas por el P. Olmedo y evitar expolios se firmó, dentro de este proyecto de investigación, una colaboración con el Colegio de san Estanislao de Kostka en Salamanca, depositario del archivo del P. Félix de Olmedo, para digitalizar sus investigaciones, una tarea ya realizada que se irá ofreciendo a través de la referida página web.

En el año 2003 este proyecto fue galardonado con la «Beca Alarcos» promovida por la prestigiosa Fundación Príncipe de Asturias para premiar trabajos de investigación histórico-literaria. Tal concesión corrobora la importancia que el teatro latino-español, durante mucho tiempo olvidado, está cobrando en la actualidad dentro del mundo del hispanismo. Esta ponencia ha de entenderse, por tanto, en el contexto de este amplio y ambicioso proyecto de investigación.

\section{Metodología y precisiones terminológicas}

Pretender abordar en los límites de una ponencia la "Propaganda ideológica en el teatro neolatino de los colegios de jesuitas en el Siglo de Oro español» es, sin duda, un objetivo inabarcable, por lo que ha de ser una visión incompleta, aunque espero que no condicione las conclusiones, antes bien un análisis más exhaustivo y extenso de los materiales las confirmaría con mayor contundencia argumental. Espigaré, pues, tan solo alguno de los aspectos más relevantes de esta orientación didáctica que dieron los

(4) Félix G. OLMEDO, Las fuentes de "La Vida es Sueño", Madrid, Voluntad, 1928, particularmente las pp. 115-188. 
jesuitas españoles — si bien las mismas conclusiones se podrían extraer quizás de las obras de teatro que los dramaturgos jesuitas escenificaron en otros países tanto europeos como de Hispanoamérica(5) —. Para este propósito me fijaré en uno de los subgéneros dramáticos donde, a mi juicio, aparece con mayor claridad la función propagandística del teatro jesuítico; me refiero a las comedias hagiográficas.

Siguiendo la pedagogía escolástica creo que es necesario explicar el contenido semántico de los términos que aparecen en el enunciado de esta ponencia. Por "propaganda ideológica» entiendo el universo cristiano con que la educación jesuítica reviste sus enseñanzas en los colegios durante ese período de la cultura española que denominamos Siglo de Oro o Edad de Oro. Ese universo cristiano abarca dos aspectos: lo espiritual y lo académico; en este sentido el teatro jesuítico entronca con el teatro universitario renacentista que emerge en Centro-Europa siguiendo el marbete erasmista del Litterae et pietas. El teatro jesuítico español es, por tanto, deudor, en sus orígenes, a una corriente que desde Europa irradia por todo el continente esta singular pedagogía que asumió la Compañía de Jesús. Precisamente las primeras obras escenificadas en los colegios de jesuitas pertenecen a estos humanistas. El Euripus, del franciscano holandés Livino Brecht, y el Acolastus, de Guillermo Gnapheus, y algunas otras son la base sobre las que se apoya el incipiente teatro jesuítico español, unas obras que no estaban exentas de un fuerte contenido ideológico y que en buena medida coincidían con el universo cristiano de los jesuitas; por eso las aceptan. Se puede decir que el teatro jesuítico español, desde el principio, acentuó de manera especial servir a la formación espiritual de las gentes que acudían a

(5) Una simple ojeada al repertorio bibliográfico elaborado por Nigel GRIFFIN (Jesuit School Drama. A Checklist of critical Literature, Londres, 1976) lo corrobora. Particular interés tienen los estudios dedicados al teatro jesuítico en Alemania por Jean Marie VALENTIN; entre sus publicaciones habría que destacar, en este sentido, su Les jésuites et le théâtre (1554-1680). Contribution à l'histoire culturelle du monde catholique dans le Saint-Empire romain germanique, Paris, Éditions Desjonquères, 2001; como 'teatro de evangelización' caracterizó Othon ARRÓNIZ al teatro representado por determinadas órdenes religiosas en la evangelización del Nuevo Mundo; la tercera parte del trabajo (pp. 138-182 está dedicada al 'teatro jesuita' (Teatro de evangelización en nueva España, México, UNAM, 1979). 
aquellas representaciones, unos espectadores que eran en primer lugar los alumnos a los que se unían sus familiares y una buena parte de las gentes de la villa o ciudad donde estaba ubicado el colegio. Este didactismo espiritual tendrá un fuerte contenido moral y dogmático en consonancia con la espiritualidad ignaciana y a la vez siguiendo las orientaciones dogmáticas del Concilio de Trento; por tanto, la idea que pretendo resaltar es cómo el teatro jesuítico es portador de las orientaciones ascético-místicas pergeñadas por san Ignacio en sus Ejercicios Espirituales sin olvidar la orientación contrarreformista que caracterizó a la Compañía de Jesús.

\section{Teatro y púlpito: la obra dramática como sermón disfrazado}

Desde que Horacio asignó a la literatura la doble finalidad de aprovechar y deleitar (prodesse et delectare), la crítica literaria estableció una especie de dicotomía entre el fondo y la forma; el fondo sería el contenido ideológico y la forma el revestimiento donde habría de residir fundamentalmente el arte literario. Pues bien, aprovechar y deleitar van a ser dos categorías que atraviesan la pedagogía del teatro jesuítico. Es más; podríamos decir que el dramaturgo del teatro jesuítico establece, en líneas generales, una primacía del aprovechamiento por encima del deleite. Los dramaturgos jesuitas utilizarán el teatro como un auxiliar pedagógico, un método que ellos heredan del teatro universitario. Y dentro de este aprovechamiento los contenidos doctrinales que configuran el universo cristiano serán los prioritarios. Lo dice muy claramente uno de los primeros dramaturgos del teatro jesuítico español. Es el P. Juan Bonifacio quien lo recuerda en algunos de sus prólogos o argumentos.

Vos seréis el argumento

y el thema de este sermón

disfrazado, Vos, divino sacramento(6).

(6) P. JUAN BONIfACiO, Códice de Villagarcía, Biblioteca Real de la Historia, Ms. 9/2565, fol. $204 \mathrm{v}$. 
En el Prólogo a la Actio quae inscribitur nepotiana, de nuevo el P. Bonifacio advierte que los alumnos de los colegios de Jesús y de san Gil en Ávila son aún principiantes en su formación en las artes sermocinales; a pesar de ello intentarán hacer algo provechoso:

[...] Por tanto, los estudiantes

de Jesús y de san Gil

traen una cosa vil

y propia de estudiantes [...].

Es un sermón disfraçado;

hablan burlando y de veras;

entre cosas plazenteras

el provecho irá mezclado(7).

La preocupación docente la tuvo más clara aún el P. Acevedo, a quien se considera el primer dramaturgo jesuita español; en el prólogo a la Comedia Metanea deja muy explícita su concepción del teatro como género donde el dramaturgo debe preocuparse sobre todo de transmitir una sana doctrina antes que someterse a las leyes de la estética. Para el P. Acevedo el aprovechamiento ascético y doctrinal del universo cristiano ha de anteponerse al deleite, es decir, lo moral tiene prioridad sobre lo artístico.

Contaros he una historia en breve suma, la cual veréis después representada, porque lo que se ve a los ojos mueve mucho más que lo que al oído damos. El grande observador de aqueste arte no me diga: 'aquí faltó el decoro'; 'mejor esotro fuera'; bien entiendo faltar en mucho y no llegar con muchas partes al decoro antiguo, mas túvose atención más al provecho poniéndolo delante de los ojos, que no al arte servir curiosamente ${ }^{(8)}$.

(7) P. JUAn BOnifacio, Códice de Villagarcía, Biblioteca Real de la Historia, Ms. 9/2565, fol. $137 \mathrm{r}$.

(8) P. Pedro Pablo ACEVEDo, «Prólogo» a Philautus, Biblioteca Real de la Historia, Ms 9/2564, fol. 2r; edición de Vicente PICÓN GARCÍA et alii, Teatro escolar latino del s. XVI: La 
La misma concepción del teatro mantiene en el 'Argumento' de la Comoedia Charopus:

[...] Y si esto es ansí, mire cada cual de todo lo que aquí representaren qué es lo que le toca y no imagine ser fábulas de vana Poesía, ni ponga su atención en mirar las peregrinas vestiduras y atavíos, mas su estudio todo sea en conferir la forma de su vida con la imagen de aquesta acción( ${ }^{(9)}$.

De esta manera, el P. Acevedo saldría al paso de las críticas que le podrían venir de círculos academicistas que le acusarían de conculcar las leyes de la poética clásica. El teatro se convierte así en un «sermón disfrazado». Por medio de la representación escénica el dramaturgo pone sobre las tablas ejemplos de conducta, en unos casos para no seguir, en otros para ser imitados. La ejemplaridad se convierte en una de las funciones principales del teatro jesuítico, enlazando con una costumbre también muy jesuítica en sus colegios que se la conocía con el nombre de "predicar el ejemplo»; se trataba de una predicación muy singular que tenía lugar los lunes, miércoles y viernes durante la cuaresma ante un público escolar. El tema era muy sencillo: un ejemplo que estimulaba el ejercicio de la virtud, o un ejemplo de conducta aberrante que había destruido al protagonista por seguir los imperativos de los enemigos del alma, es decir, el demonio, el mundo y la carne ${ }^{(10)}$. Pero, sin duda, el autor que dejó una mayor huella de la piedad

obra del Pedro Pablo de Acevedo. Lucifer Furens, Occasio, Philautus, Charopus, Madrid, Ediciones Clásicas, 1997, p. 332.

(9) Ibidem, fol. 169v-170r; edic. cit. de PICÓN, p. 451.

(10) La Biblioteca Universitaria de Salamanca custodia dos códices que recogen los ejemplos predicados en el colegio jesútico de san Estanislao. En un trabajo publicado hace algunos años propuse la vinculación genética del tema del «don Juan" con un ejemplo que lleva por título "El tema de don Juan" (véase Jesús MENÉNDEZ PELÁEZ, "El tema de don Juan en la predicación de los Siglos de Oro", Archivum, XXXIX-XL (1989-90)365-383). De la asistencia de un público escolar a estas predicaciones da testimonio el estudiante italiano Girolamo da 
jesuítica no solo entre los estudiantes de los colegios de jesuitas del Siglo de Oro, sino entre otras congregaciones religiosas tanto seculares como regulares fue el P. Alonso Rodríguez (1538-1616) con su Ejercicio de perfección y virtudes cristianas; sus pláticas terminan siempre con el epígrafe «En que se confirma lo dicho con algunos ejemplos»; decenas y decenas de ejemplos va refiriendo el jesuita para recordar determinados momentos de la vida de los santos que el autor considera modelos de conducta para ser imitados por los jóvenes estudiantes; su obra puede ser considerada como un verdadero ejemplario.

Es la misma actitud que adopta el P. Acevedo con su teatro; en el Argumento a su Comedia Metanea el dramaturgo actúa como un predicador:

Oiréis exhortaciones a la penitencia veréis sus lágrimas con que la triste suerte de aquellos llora a quien la trina peste - demonio, mundo y carne - oprime y vence ${ }^{(11)}$.

No es de extrañar que los historiadores de la Compañía de Jesús, al referirse al P. Acevedo escriban: «[El P. Acevedo] trocó los teatros en púlpitos, y salían los hombres muchas veces más recogidos y llorosos de sus representaciones, que de los sermones de algunos excelentes predicadores»(12).

Aunque quizá no se pueda aplicar esta concepción del teatro que tiene el P. Acevedo a la totalidad de los dramaturgos de la Compañía, sí nos vale para marcar la orientación que los dramaturgos del teatro jesuítico dieron a sus representaciones escolares: el teatro había de ser un auxiliar de su pedagogía académica y sobre todo espiritual. «Trocó los teatros en púlpitos»;

Sommaia, quien realizó estudios en Salamanca; del impacto que tales ejemplos producían en su espíritu dejó testimonio en su diario (véase Diario de un estudiante de Salamanca, edición e introducción de George HALLEY, Universidad de Salamanca, 1977.

(11) P. ACEVEDO, "Prólogo» a Comoedia Metanea, Biblioteca Real de la Historia, Ms. 9/2564, fol. 201r; edic. de julio ALONSO ASENJO, Comedia Metanea, en La Tragedia de san Hermenegildo y otras obras del Teatrio Español de Colegio, Sevilla-Valencia, UNED, vol. II, p. 115.

(12) P. Pedro DE RIBADENEYRA, Historia de la asistencia, 1, V, c. 12, citado en Antonio ASTRÁIN, Historia de la Compañía de Jesús en la Asistencia de España, Madrid, Razón y Fe, 1914, vol. 2, p. 587. 
esto es, el teatro había de cumplir la función asignada al púlpito, y desde el púlpito el predicador enseñaba las verdades del universo cristiano en su doble aspecto: moral y dogmático.

\section{El teatro jesuítico, la espiritualidad ignaciana y el Concilio de Trento}

Los dramaturgos del teatro jesuítico intentarán expandir este universo cristiano a través de sus creaciones dramáticas, que amenizaban las principales efemérides del calendario litúrgico y escolar; dentro del amplio corpus que conforman el teatro jesuítico español me fijaré, para el objetivo propuesto, en el teatro hagiográfico.

La literatura hagiográfica en sus distintos géneros tiene un fundamento teológico que no se puede obviar si se pretende comprender en su total significación la creación literaria. La hagiografía literaria descansa y se apoya en una teología de los santos. Podemos afirmar, como punto de partida, que el sensus fidelium, esto es la liturgia, primero, la especulación teológica, en segundo lugar, y finalmente la doctrina conciliar atribuyen a los santos dos funciones que servirán de inspiración al hagiógrafo: la ejemplaridad y el poder de intercesión.

La ejemplaridad se fundamenta en el hecho de que los santos, como seres humanos que fueron, estuvieron revestidos de una naturaleza humana herida y dañada por el pecado original, una lacra que ellos supieron superar merced a un programa de perfección ascética impuesto por el imperativo evangélico de "sed perfectos como vuestro Padre celestial es perfecto» (Mat., 5, 48); esta perfección tiene un único modelo de imitación: la figura de Cristo, — «nadie llega al Padre, el tres veces santo, sino por mí» (Jn, 8, 12) - a quien la teología reviste de una doble naturaleza: humana y divina; esta doble naturaleza planteó graves polémicas en los primeros siglos del cristianismo. Recuérdese el arrianismo y sus secuelas en la historia de la teología; porque Cristo es hombre y, por tanto, copartícipe de nuestra 
humanidad, Cristo será el modelo ejemplar que se ha de imitar. De la imitación de Cristo así reza el título de una de las obras de mayor impacto en la piedad popular desde el Siglo de Oro hasta nuestros días; su autor, Tomás de Kempis, un apellido que dio título también a la obra, El Kempis. El ser humano que encarna en su proyecto existencial esta imitación de Cristo se convierte en santo; la teología paulina está llena de imágenes metafóricas y de comparaciones para expresar esta idea: "Revestíos del Señor Jesucristo» (Rom., 13, 14); la vida del cristiano ha de sumergirse en Cristo, como injertada en la suya: "Vivo yo, pero no yo, que es Cristo quien vive en mi» (Gal., 2, 20); la santidad ha de ser, pues, la aspiración de todo cristiano, esto es, imitar a Cristo; el programa que lleva a la consecución del título de santidad está contenido en el sermón de la montaña: son las bienaventuranzas. Este será el programa sobre el que versará el juicio final. Por eso la liturgia, el sensus fidelium, se sirve de este texto evangélico para festejar el día de Todos los Santos (1 de noviembre). El santo se convierte así en el modelo de alumno ejemplar que ha sabido imitar a su maestro y superar con éxito el curso existencial de la vida. Por eso la Iglesia, desde sus inicios, utilizará el santoral como paradigma o modelo del curricullum vitae del cristiano.

El poder de intercesión de los santos fue tratado por la especulación teológica de manera particular por santo Tomás de Aquino en la STh, 22- q. 83, a.12; este artículo lleva por título "Utrum sancti qui sunt in patria orent pro nobis»; santo Tomás responde afirmativamente; los santos tienen poder de intercesión por varias razones:

$1^{\circ}$ Quia cum oratio pro aliis facta ex caritate proveniat, ut dictum est, quanto sancti qui sunt in patria sunt perfectioris caritatis, tanto magis orant pro viatoribus...

$2^{\circ}$ Quod sanctis qui sunt in patria, cum sint beati, nibil deest nisi gloria corporis, pro qua orant; orant autem pro nobis, quibus deest beatitudinis ultima perfectio; et eorum orationes habent efficatiam impetrandi ex praeceptibus eorum meritis et ex divina aceptatione... 
$3^{\circ}$ Quia sancti viventes meruerunt ut pro nobis orarent ideo eos invocamus nominibus quibus bic vocabantur, quibus etiam nobis magis innostescunt...(13)

La argumentación teológica justifica de esta manera el patronazgo que desde el primitivo cristianismo la Iglesia concedió a los santos; el primero de estos patronazgos se refiere al bautismo. La Iglesia, a través del derecho canónico, determina que:

Curent parochi ut ei qui baptizatur, christianum imponatur nomen; quod si id consequi non poterunt, nomini a parentibus imposito addant nomen alicuius Sancti et in libro baptizatorum utrumque nomen perscribant ${ }^{(14)}$.

La misma legislación eclesiástica, basándose en el poder intercesor de los santos, aconseja que las distintas agrupaciones humanas, desde las propias naciones hasta las agrupaciones gremiales, elijan a un santo como patrono a quien invoquen como intercesor ante la divinidad:

Laudabiliter quoque servatis servandis sancti nationum, dioecesium, provinciarum, confraternitatum, familiarum religiosarum aliorumque locorum et moralium personarum eliguntur et, accedente confirmatione Sedis Apostolicae, constituuntur Patroni(15).

El Concilio de Trento, máximo exponente de la Contrarreforma, sistematiza ya de manera mucho más clara la teología de los santos en su intento por salir al paso de las aberraciones de las doctrinas protestantes, cuya historia salutis desconoce el papel soteriológico de los santos; el 3 de diciembre

(13) SANTO TOMÁS DE AQUINO, Summa Theologica, editio cura Fratrum eiusdem Ordinis, Madrid, BAC, III, 1952, pp. 550-551

(14) Código de Derecho Canónico, edic. de Lorenzo MIQUÉLEZ DOMíNGUEZ- Sabino ALONSO MORÁN — Marcelino CABREROS ORTIZ, Madrid, BAC, 1962, art. 761, p. 292.

(15) Ibidem, art. 1.278 p. 484 
de 1563 se aprueba el Decretum de invocatione, veneratione et reliquiis Sanctorum et sacris imaginibus en los siguientes términos:

Mandat sancta Synodus omnibus episcopis et ceteris docendi munus cu109 ramque sustinentibus, ut iuxta catbolicae et apostolicae Ecclesiae usum, a primaevis christianae religionis temporibus receptum, sanctorumque Patrum consensionem et sacrorum conciliorum decreta: imprimis de Sanctorum intercessione, invocatione, reliquiarum bonore, et legitimo imaginum usu fideles diligenter instruant, docentes eos, Sanctos, una cum Christo regnantes, orationes suas pro bominibus Deo offerre; bonum atque utile esse, suppliciter eos invocare et ob beneficia impetranda a Deo per Filium eius Iesum Christum Dominum nostrum, qui solus noster Redemptor et Salvator est, ad eorum orationes, opem auxiliumque confugere; illos vero, qui negant Sanctos, aeterna felicitate in caelo fruentes, invocandos esse, impie sentire ${ }^{(16)}$.

Por tanto, el Concilio sanciona con un «impie sentire» la negativa protestante a considerar que los santos tienen poder de intercesión. El Concilio asimismo justifica el culto que se debe a las reliquias y a las imágenes de los santos con una precisión terminológica que impide establecer equivalencias semánticas con los ídolos paganos, objeción propuesta por los detractores de este culto de dulía.

La iconografía hagiográfica - pintura, escultura, grabados - que caracteriza a nuestro barroco arranca, a mi juicio, de la siguiente disposición tridentina:

Imagines porro Christi, Deiparae Virginis et aliorum Sanctorum in templis prasertim habendas et retinendas, eisque debitum honorem et venerationem impertiendam, non quod credatur inesse aliqua in is divinitas vel virtus, propter quam sint colendae, vel quod ab eis sit aliquid petendum, vel quod

(16) DENZINGER, Henricus- SCHÖNMETZER, Adolfus, Enchiridion Symbolorum Definitionum et Declarationum de Rebus Fidei el Morum, Barcinone, Herder, 1965, p. 419. 
fiducia in imaginibus sit figenda, veluti olim fiebat a gentibus, quae in idolis spem suam collocabant: sed quoniam honos, qui eis exbibetur, refertur ad prototypa, quae illae repraesentant: ita ut per imagines, quas osculamur et coram quibus caput aperimus et procumbimus, Christum adoremus, et Sanctos, quórum illae similitudinem gerunt, veneremur. Id quod Conciliorum, praesertim vero Nicaenae Synodi, decretis contra imaginum oppugnatores est sancitum. (17)

Quiero llamar la atención en otra disposición recogida por este decreto tridentino en relación con la literatura hagiográfica. Es una exhortación a que los obispos y rectores de las iglesias utilicen las artes, tanto literarias como pictóricas, para instruir a los fieles en esta doctrina hagiográfica:

Illud vero diligenter doceant episcopi, per historias mysteriorum nostrae redemptionis, picturis vel aliis similitudinibus expressas, erudiri et confirmari populum in articulis fidei commemorandis et assidue recolendis; [...] quia Dei per Sanctos miracula et salutaria exempla oculis fidelium subiciuntur, ut pro iis Deo gratias agant, ad Sanctorumque imitationem vitam moresque suos componant, excitenturque ad adorandum ac diligendum Deum et ad pietatem colendam. Si quis autem his decretis contraria docuerit aut senserit: anathema sit(18).

Todo esto explica la gran eclosión del culto de dulía con que la liturgia católica venerará a los santos a partir del Concilio de Trento; la riqueza artística que generó la hagiografía durante nuestro barroco es uno de los testimonios más singulares de los países católicos, de manera muy especial en España; la literatura, la música y las artes plásticas, al unísono, crearon un patrimonio cultural que no tiene parangón en ningún otro país.

(17) DENZINGER, Henricus; SCHÖNMETZER, Adolfus, Enchiridion Symbolorum Definitionum et Declarationum de Rebus Fidei el Morum, Barcinone, Herder, 1965, p. 420.

(18) Ibidem, p. 420. 


\section{La espiritualidad ignaciana a través del teatro hagiográfico jesuita}

Que la Compañía de Jesús jugó un papel preponderante en el desarrollo doctrinal del Concilio de Trento es algo bien conocido. Los Papas - Paulo III, Julio III, Marcelo II y Paulo IV - , que presidieron las distintas convocatorias de las sesiones tridentinas, sintieron una predilección y simpatía especiales por la nueva savia que traía aquella nueva congregación; una simple lectura de las sesiones tridentinas lo deja bien claro. Los teólogos jesuitas jugaron un papel determinante en el Concilio de Trento(19). De esta manera la Compañía de Jesús, nacida al calor de las doctrinas tridentinas como órgano oficial de la Contrarreforma, habría de tener muy en cuenta las orientaciones conciliares sobre el carácter modélico de los santos en la vida espiritual y a la vez seguir las singularidades espirituales con que la diseñó su fundador. Los jesuitas dieron un fuerte impulso a la literatura hagiográfica en los distintos géneros literarios; particular importancia tiene la obra hagiográfica del P. Pedro de Rivadeneyra con sus vidas de san Ignacio o san Francisco de Borja y, sobre todo su Flos Sanctorum [a. 1599], una obra de lectura frecuente en la espiritualidad católica desde el Siglo de Oro hasta los tiempos modernos. El teatro hagiográfico jesuítico ha de entenderse, pues, en este contexto de las doctrinas tridentinas y de la espiritualidad ignaciana.

(19) Dos nombres jesuitas van unidos al desarrollo de Trento: los PP. Diego Laínez y Alfonso Salmerón. Son los consultores habituales del Papa y de los obispos en las cuestiones más espinosas, como el tema de la justificación. La discusión entre el P. Laínez y el P. Seripando es uno de los capítulos más significativos de esta impronta del jesuitismo en Trento al dejar su sello en el decreto sobre la justificación frente a la teoría de Seripando que será calificada como la teoría camuflada de Lutero. La misma impronta dejaron los jesuitas en la teoría sacramentaria. El espíritu que se respiraba en el aula conciliar era claramente contrarreformista; lo prueba el "modus operandi" del concilio; todas las sesiones comenzaban con la intervención de los teólogos encargados de analizar la posición protestante para proponer a continuación la doctrina católica. En este análisis preliminar los teólogos jesuitas llevarán con frecuencia la iniciativa. 
Ante la imposibilidad de hacer un estudio individualizado de la propaganda ideológica en las distintas comedias hagiográficas tan solo ofreceré las características generales más significativas a modo de una tipología del santo en el teatro jesuítico donde se ve cómo la Compañía de Jesús utiliza el teatro como instrumento de propaganda ideológica de ese universo cristiano, moral y dogmático, a través de la puesta en escena de la vida de unos santos que resultan ejemplares para ser imitados por la pléyade de alumnos que acudían a sus colegios.

\subsection{Verosimilitud histórica}

La elección del personaje modelo estará condicionada por el espectador al que se dirige, esto es, un público prioritariamente estudiantil. Se trata, por tanto, de un teatro escolar ${ }^{(20)}$. Los modelos que se presentan han de tener un currículo existencial que presente unas condiciones sociales y ambientales que puedan ser verosímiles para unos jóvenes estudiantes del Siglo de Oro. De esta manera el mensaje ideológico que se pretende transmitir se hace creíble. Por ello la primera característica que ha de tener la obra literaria que se presenta, con una finalidad prioritariamente docente, es la verosimilitud histórica. De ahí que las hagiografías del teatro jesuítico tengan un trasfondo histórico que el hagiógrafo y dramaturgo seguirá con bastante fidelidad; téngase presente que algunas de estas hagiografías se escriben muy poco tiempo después de la muerte de los protagonistas; una gran parte de los espectadores habían conocido y tratado a los protagonistas; por tanto, el dramaturgo pretende escribir una biografía dramatizada. De esta manera el mensaje será más favorablemente acogido. Por otra parte, el hagiógrafo y dramaturgo elegirá dentro del santoral aquellos santos que

(20) Sobre la impronta pedagógica de este teatro escolar véase Jesús MENÉNDEZ PELÁEZ, J. Los jesuitas y el teatro... pp. 31-97; también IDEM, "El teatro escolar latino-castellano en el siglo XVI», en Javier HUERTA CALVO (Dir.), Historia del Teatro Español, Madrid, Gredos, vol. I, 2003, pp. 581-608. 
por sus circunstancias ambientales e históricas pudieran mejor adecuarse a la realidad existencial de los espectadores del Siglo de Oro. Si al mismo tiempo esos santos nacieron en el seno de la propia Compañía, la impronta docente y pedagógica será más eficiente. De ahí que una buena parte del teatro hagiográfico jesuítico tenga como protagonistas a beatos o santos salidos de la Compañía, empezando por el su Fundador.

Ignacio de Loyola, Luis Gonzaga, Francisco de Borja, Estanislao de Kostka, alcanzan la aureola de santidad en el seno de la Compañía. Sus vidas fueron utilizadas por el teatro jesuítico del P. Diego Calleja ${ }^{(21)}$. Era algo esperado, por lo que vengo diciendo, que el dramaturgo jesuita utilice sus esquemas existenciales para presentarlos como modelos que podían ser imitados por la pléyade de estudiantes y de jóvenes novicios que recibían aquellas enseñanzas(22); unas enseñanzas que provocaron celos y recelos con la universidad pública; estas pugnas y polémicas son testimonio del gran éxito que alcanzó aquella pedagogía(23). Los dramaturgos del teatro jesuítico aprovecharán esta favorable acogida que tuvieron sus colegios en la España del siglo XVI para, a través del teatro, formarles en letras y en espiritualidad, según el ya conocido marbete de Erasmo del litterae et pietas. En otro lugar ya analicé detenidamente la función docente y las características tipológicas que tiene el teatro jesuítico ${ }^{(24)}$.

(21) Hay dos padres jesuitas que llevan el nombre de Diego Calleja, lo que da origen a confusiones. Ya Cayetano Alberto de la Barrera y Leirado (Catálogo del Teatro Antiguo Español, [1860], edic. facsímil, Madrid, Gredos, 1969, pp. 59-60) advirtió esto; los dos trataron el tema hagiográfico en el teatro. El códice que se conserva en la Biblioteca Real de la Historia lleva en el lomo el título de Comedias del P. Calleja. Este padre, del que no tengo más noticias, es autor de las comedias arriba señaladas. La que se refiere al fundador de la Compañía, está fechada en 1609, y está dedicada a festejar la beatificación del fundador que tiene lugar precisamente el 15 de noviembre de ese año. La comedia referida termina con este colofón: "Acabose de componer a gloria de Dios y nuestro Beato y Padre Ignacio a 20 de Diciembre de 1609".

(22) Bernabé BARTOLOMÉ MARTíneZ, Historia de la Acción Educadora de la Iglesia en España, Madrid, BAC, 1995, p. 663

(23) Biblioteca Real de la Historia, Sección Jesuitas, Legajo 48 s/c citado por Bernabé, 1995 , p. 663.

(24) Jesús MENÉNDEZ PELÁEZ, Los jesuitas y el teatro...[1995] y «El teatro escolar latinocastellano... [2003]. 


\subsection{El santo como modelo de fortaleza}

El título que el P. Diego Calleja asigna a la hagiografía sobre san Ignacio ya es bien significativo: El Triunfo de Fortaleza; la fortaleza como virtud cristiana la prodiga san Ignacio sobre todo para afianzarse en la vocación jesuítica. Con frecuencia el joven que deseaba entrar en religión podía encontrarse con la negativa de su familia, particularmente del padre. El propio san Ignacio hubo de intervenir personalmente en alguna ocasión para resolver un conflicto familiar en que el padre de un muchacho se oponía a que su hijo profesara en la Compañía; en aquella ocasión Ignacio de Loyola escribe una larga carta que es una disertación sobre la fortaleza que los jóvenes han de tener para defender su vocación religiosa frente a los imperativos familiares ${ }^{(25)}$. En los catecismos de la época, tanto en el del P. Astete ${ }^{(26)}$ como en el del P. Ripalda(27) se considera a la Fortaleza como una de las virtudes cardinales y uno de los dones del Espíritu Santo. La Fortaleza será, siguiendo la presencia de personajes alegóricos que prodigó siempre el teatro jesuítico, uno de los personajes centrales de la obra. Los jóvenes novicios que se decidían a entrar en la nueva Congregación necesitaban un modelo a seguir. El hagiógrafo del teatro jesuítico les propone el ejemplo del propio fundador. El hagiógrafo y dramaturgo quiso sazonar esta obra dramática, estructurada en tres largas jornadas, con un acentuado verismo histórico; los personajes representan el entorno existencial en el que vivió Ignacio a partir del cerco de Pamplona por los franceses con que se inicia la obra: Diego Laínez, Salmerón, Francisco Javier son algunos de los personajes que revestidos con el don de la Fortaleza consiguen vencer al Demonio, La Carne, Lutero, La Herejía y la Gentilidad.

(25) SAN IGNACIO DE LOYOLA, Obras Completas, edic. de Ignacio IPARRAGUIRRE- Cándido de DALMASES y Manuel RUIZ JURADO, Madrid, BAC, 1991, pp. 964-965.

(26) P. ASTETE, Catecismo de la doctrina cristina, Madrid, Maeva, 1997, pp. 31-32

(27) P. RIPALDA, Catecismo de la doctrina cristiana, Madrid, Maeva, 1997, p. 42 


\subsection{El santo como modelo de renuncia al estatus social de la familia}

Luis Gonzaga, Francisco de Borja (1510-1572) y Estanislao de Kostka, nacidos a la vida espiritual en el seno de la Compañía, serán referentes constantes en la vida de esta Congregación desde sus inicios hasta los tiempos modernos; la iconografía que adorna iglesias, pasillos y estancias de los actuales colegios de jesuitas no es más que el testimonio del fervor que estos primeros jesuitas suscitaron entre sus correligionarios. Tres vidas muy singulares. Los tres eran de procedencia noble y habían experimentado los loores de la vida cortesana.

Luis Gonzaga era el mayor de los hijos de una influyente familia cortesana en la Lombardía italiana; desde muy joven se sintió atraído por la vida espiritual, lo que ponía en peligro las pretensiones que su padre había depositado en él; en vano intenta halagarle con todos los placeres de la vida nobiliaria europea para disuadirle de aquella vocación religiosa; placeres, honores, seducciones sexuales y glorias no lograron cambiar la decisión de entrar en religión bajo los auspicios de Ignacio de Loyola. La decepción de su padre, que había hecho lo indecible para que su hijo Luis desistiese de entrar en religión, queda patente en la carta que escribe al padre Claudio Acquaviva, General del noviciado jesuítico donde entra Luis: "Hago saber a vuestra señoría reverendísima que le entrego lo que más quiero en este mundo y la mayor esperanza que tenía para la conservación de mi casa»(28). Como puede verse, se trababa de una vida que para los rectores de la Compañía resultaba ejemplar y modélica a través de la cual se podía transmitir una propaganda de las verdades morales y dogmáticas del universo cristiano. De ahí que los dramaturgos y hagiógrafos del teatro jesuítico la hayan utilizado como fuente de inspiración para su teatro. Dos comedias del P. Salas (Coloquio del primer estudiante y mayorazgo trocado, beato Luis Gonzaga y El estudiante soldado que es la niñez del beato Gonzaga)

(28) «San Luis Gonzaga» en AA. VV., Año cristiano, Madrid, BAC, II, 1959, p. 712 
y un diálogo del P. Ximeno del colegio de Aragón (Diálogo del beato Luis Gonzaga) ${ }^{(29)}$, además de poemas sueltos, testimonian el carácter ejemplar y modélico que la vida de Luis Gonzaga tenía para los alumnos y novicios de los colegios de jesuitas. Estas obras recalcan varias virtudes que a juicio de los dramaturgos resultaban modélicas y que, por tanto, habían de imitar los estudiantes de la Compañía. Una de ellas era la castidad, el personaje alegórico quizás más importante en ellas; el padre de Luis, en su intento para que desistiera de entrar en religión y se ocupase de su casa como mayorazgo que era, le había hecho rodear de un ambiente cortesano poco propicio para conservar la virginidad; sin embargo, el joven Luis se mantuvo fiel a sus ideales; de esta manera pasó a ser considerado como modelo de castidad. La segunda virtud que los citados dramaturgos presentan como modélica y ejemplar en Luis Gonzaga es la milicia cristiana, una vieja alegoría bíblica que pasa al cristianismo, bajo la metáfora del miles christianus que defiende el reino de Dios y que tomará cuerpo estamental y social en las llamadas órdenes militares desde la Edad Media hasta la Ilustración. Fue esta una idea muy querida por Ignacio de Loyola. Recuérdese que la Bula fundacional de la Compañía de Jesús de 1540 lleva por título Regimini militantis Ecclesiae y que "cualquiera que entre en nuestra Compañía ha de ser soldado de Dios bajo la bandera de la Cruz" ("Quicumque in Societate nostra, quam Iesu nomine insigniri cupimus, vult sub crucis vexillo Deo militari»; el «miles christianus» será uno de los ingredientes de ese universo cristiano; los miembros de la Compañía han de ser ante todo soldados de Cristo. La ascética ignaciana es una lucha entre dos realidades o fuerzas antitéticas, el Bien y el Mal; son como dos ejércitos, capitaneados por dos jefes militares, Cristo y el Demonio. Es este el núcleo de una de las meditaciones más originales de los Ejercicios Espirituales conocida como «la de las dos banderas». Es, asimismo, la idea motriz que aparece constantemente como el núcleo o leit-motiv de la acción dramática del teatro hagiográfico jesuítico. El escenario es como un campo de batalla en donde lidian dos

(29) Biblioteca Real de la Historia, Ms. 9/2571 
ejércitos que enarbolan su propia bandera para llevarse a su lado al protagonista. Los numerosos personajes de que constan las hagiografías del teatro jesuítico serán militantes de una de estas dos fuerzas o banderas; la alegoría será el recurso dramático habitual para crear unos personajes que representan vicios y virtudes en aquellos escenarios del teatro escolar. Luis Gonzaga fue modelo de «estudiante soldado» bajo la bandera de Cristo.

Estas mismas características presentan las comedias hagiográficas sobre Francisco de Borja y Estanislao de Kostka que omito.

Continuando con las hagiografías del P. Calleja nos encontramos ahora con otros modelos muy distanciados en el tiempo de los santos anteriormente presentados como ejemplos que deben ser imitados. Hasta ahora hemos aludido a santos nacidos al socaire de la Compañía; fueron, sin duda, los más modélicos y ejemplares para transmitir la propaganda ideológica del universo cristiano; pero el repertorio había de ampliarse; por eso el hagiógrafo y dramaturgo elegirá dentro del santoral aquellos santos que por sus circunstancias ambientales e históricas pudieran mejor adecuarse a la realidad existencial de los espectadores del Siglo de Oro; de nuevo nos encontramos con que los santos elegidos para la comedia hagiográfica fueron santos cuya conducta religiosa había provocado un conflicto familiar. El mensaje propagandístico es muy claro: los imperativos religiosos han de estar por encima de los proyectos sociales de la voluntad paterna. Este será el mensaje que el dramaturgo intentará transmitir con dos modelos de santos, cuyas coordenadas existenciales se enmarcan en la Roma Imperial de Teodosio el Grande (347-395) y Honorio (384-423); estamos, pues, a finales del siglo IV y principios del V. La paz de Constantino (306-337) había hecho del cristianismo la religión del Imperio; era la primera célula de lo que después se llamó el nacionalcatolicismo que tendrá en Carlos V y, sobre todo, en Felipe II una verdadera continuación. Mutatis mutandis, el dramaturgo del teatro jesuítico busca un pasado con unas ciertas analogías con el momento en el que él escribe. El santoral recogía dos santos un tanto extraños, uno de la tradición griega y bizantina, San Juan Calibita, mientras 
el otro estaba inserto en la sociedad romana, san Alejo ${ }^{(30)}$. El dramaturgo jesuita situará a la familia de san Juan Calibita en la Roma del emperador Teodosio; la comedia nos presenta a su padre, Eutropio, en diálogo con su esposa, muy preocupados ambos por dar a su hijo un «estado conveniente» (fol. 66v). La llegada de un monje eremita a la casa del noble patricio provocará el conflicto. El joven Juan abandonará su casa para seguir los postulados de la vida eremítica; el trauma familiar resulta claro. Se fuga de la casa paterna, sin saber su paradero. Pasados los años regresará de nuevo como pobre mendigo, pidiendo limosna en su antiguo hogar, no siendo reconocido por los suyos; su propia madre le desecha, mientras su padre le acoge disponiendo una choza para él. La vida penitente que lleva conmueve a cuantos le visitan; finalmente, poco antes de morir refiere a su propia madre su verdadera identidad.

La Vida de san Alejo tiene muchos parecidos con la anterior(31). De nuevo la comedia hagiográfica jesuítica actúa de medio de propaganda de los ideales de la espiritualidad ignaciana. La renuncia a la propia familia fue objeto constante de la espiritualidad jesuítica; el ya citado P. Alonso Rodríguez dedica el Tratado Quinto del Libro II de su Ejercicio de perfección cristiana a "De la afición desordenada de parientes"; son siete capítulos en los que el jesuita habla de los peligros que puede suponer un excesivo apego a la propia familia; su reflexión está entreverada de abundantísimos ejemplos de conducta modélica no sólo de santos sino del propio Ignacio de Loyola que mostraron un cierto desarraigo con su familia. El santo del teatro jesuítico ha de ser también modelo en refrenar esta tendencia innata en el ser humano.

(30) La tradición de estos santos, particularmente de san Alejo, fue estudiada por Carlos Alberto VEGA, La vida de san Alejo. Versiones castellanas, Salamanca, Universidad, 1991. Las comedias jesuíticas referidas se encuentran en Biblioteca Nacional, Ms. 17.288, san Alejo, fols. 1r-62r; san Juan Calibita, fols. 63r-105v.

(31) Véase Jesús MENÉNDEZ PELÁEZ, "El santo peregrino en el teatro jesuítico: La vida de san Alejo, peregrino en su patria", en Homo viator. Errance, pélegrinage et voyage initiatique, Coloquio Internacional celebrado en la Universidad de Caen (Normandía), 27-28 y 29 de mayo de 2004 [en prensa]. 


\subsection{El santo como modelo de firmeza en la fe cristiana}

La espiritualidad jesuítica no podía obviar las particulares circunstancias que rodeaban la historia de la Iglesia durante el Siglo de Oro. El teatro jesuítico nos presenta a santos que han sacrificado su propia vida por defender sus creencias religiosas. Es otra de las parcelas modélicas que presenta el santo del teatro jesuítico. Hasta ahora habíamos visto santos dentro de la categoría de "confesores» o "Vírgenes», ahora nos adentramos en la categoría de los santos «mártires». San Hermenegildo, san Pedro Mártir, santa Catalina de Alejandría, santa Cecilia, san Tiburcio y san Vicente y hermanos son los puntos de mira de los dramaturgos del teatro jesuítico.

En la Tragedia de san Hermenegildo, una de las obras mejor logradas no sólo del teatro jesuítico sino del teatro renacentista español, el mensaje ideológico que se quiere transmitir es muy claro: los imperativos religiosos han de estar por encima de la voluntad paterna. Hermenegildo aceptará el martirio, renunciará a los vínculos familiares antes de claudicar de su fe. Las analogías que planteaba el hecho histórico del siglo VI en el que se evoca el conflicto entre un padre arriano y un hijo que abjura de la religión paterna y se convierte al catolicismo guardaban estrecha relación de verosimilitud para la sociedad de finales del siglo XVI, que vivía la ruptura entre católicos y protestantes. No ha de olvidarse que tal ruptura entre católicos y protestantes fue siempre una de las grandes preocupaciones de la Compañía de Jesús, cuyo testimonio más fehaciente lo dejó el P. Pedro de Ribadeneyra en sus Historias de la Contrarreforma (32).

Dejamos a san Pedro Mártir, cuya vida sirvió de inspiración al P. Guillermo de Barceló para su Dialogus Petri Martiris certamen cum Arrianis hereticis et eiusdem mortem continens ${ }^{(33)}$ cuya finalidad es presentar la fortaleza espiritual de este santo frente a la herejía; evocamos, sin embargo, a

(32) Pedro de RIBADENEYRA, Historias de la Contrarreforma, Madrid, BAC, 1945.

(33) Biblioteca Real de la Historia, Ms. 9/2569, fols. 1r-12v. 
santa Catalina de Alejandría, una de las santas más celebradas en el teatro jesuítico, cuyos dramaturgos no hacen más que continuar una tradición que en los tiempos medievales había alcanzado su máximo apogeo; esta santa, mártir en el Imperio romano del siglo IV, fue considerada como modelo de fortaleza e ingenio en la defensa de la fe cristiana; son muchas las instituciones que ya desde la época medieval se acogieron a su patronazgo: Universidad de París, filósofos, estudiantes, molineros, carreteros... Los colegios de jesuitas celebraron siempre con un cierto boato su festividad. De ahí que los dramaturgos del teatro jesuítico se hayan inspirado en una tradición, envuelta en la leyenda, sobre la discusión que mantuvo con los filósofos gentiles y la aceptación del martirio. El P. Hernando de Ávila, autor principal de la Tragedia de san Hermenegildo, es al mismo tiempo el autor de la Tragicomedia de santa Catalina, Virgen y Mártir (34). El dramaturgo, como indica en el prólogo, pretende presentar a la santa como modelo de "virgen y esposa de Cristo" y de "fortaleza y varonil constancia / que no la puso miedo el cruel tirano / las amenazas dél ni los tormentos» (fol. 107v). A lo largo de la obra se pone de manifiesto una vez más el influjo de la imaginería presentada por san Ignacio de Loyola en los Ejercicios Espirituales bajo la iconografía de las dos banderas. Después de negarse a presentar la ofrenda a los dioses paganos, pues ella solo "a Cristo eterno y celestial esposo/ de mí le hago humilde sacrificio» se le presentan tres ángeles, uno de los cuales sostiene con la santa este diálogo:

$$
\begin{aligned}
& \text { Ángel. - Queréis, sabia Catherina, } \\
& \text { militar como guerrera } \\
& \text { debaxo de la bandera } \\
& \text { de la milicia divina? } \\
& \text { Catalina. - Sí quiero, y bien que quiera. } \\
& \text { Ángel. - ¿Proponéis de pelear } \\
& \text { y con valor conquistar } \\
& \text { por la fe de Jesucristo? }
\end{aligned}
$$

(34) De esta obra se conservan dos manuscritos: Biblioteca Nacional de Madrid, Ms. 17.288, fols. 106r-191v; Biblioteca del Colegio de san Ignacio de Alcalá de Henares, Ms. 325. Las referencias se toman del manuscrito de la Biblioteca Nacional. 


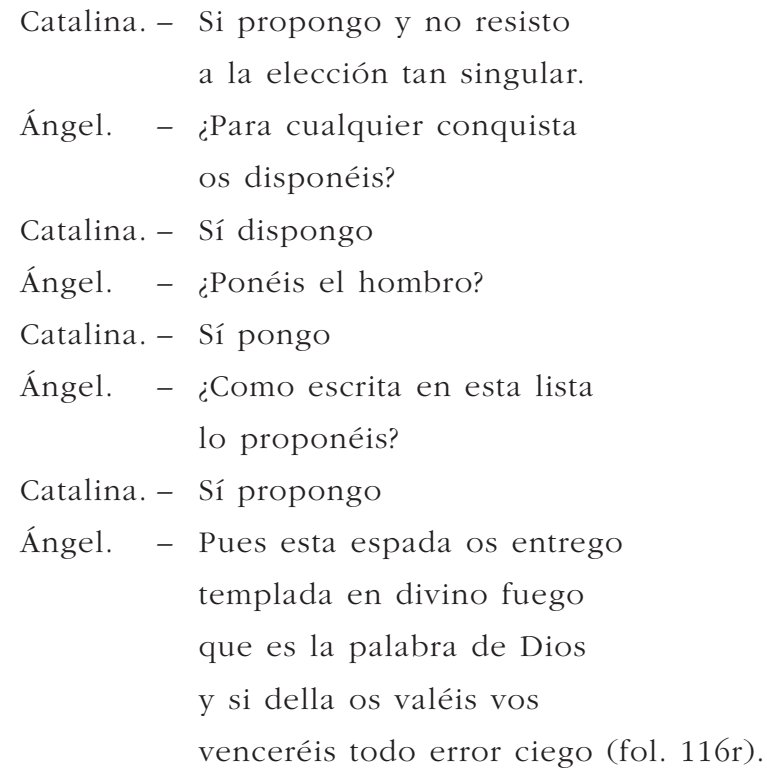

El teatro eleva a la categoría sensible, mediante la representación, una de las ideas básicas de la espiritualidad ignaciana y que forma parte del universo cristiano y caracteriza a los miembros de la Compañía de Jesús: la milicia cristiana, el "miles Christianus».

San Vicente y hermanos mártires. Los ejemplos de los hermanos Vicente, Sabina y Cristena, mártires bajo la persecución de Diocleciano, constituyen la sustancia del contenido dramático de la obra de Juan Bonifacio Tragoedia quae inscribitur vicentina ${ }^{(35)}$. Nacidos en Talavera de la Reina son ejecutados en Ávila, ciudad que los tiene como patronos y donde se levanta la basílica de san Vicente, uno de los monumentos más impresionantes del románico español. El dramaturgo jesuita, en este caso el P. Juan Bonifacio, profesor de Latín y de Retórica durante un tiempo en el colegio jesuítico de Ávila, utiliza el teatro para proponer unos modelos de conducta ejemplar en la actitud de estos tres hermanos que aceptan el martirio antes que claudicar

(35) Juan BONIFACIO, "Códice de Villagarcía», Biblioteca Real de la Historia, Ms. 9/2565, fols. $144 \mathrm{r}-168 \mathrm{r}$. 
de su fe. El universo cristiano exige la renuncia a la propia vida antes que renegar de los principios de la fe. El espíritu contrarreformista aconseja al creyente incluso perder la propia vida antes de claudicar de las propias convicciones dogmáticas; el respeto al dogma puede exigir al cristiano la renuncia a la propia existencia. La naturaleza juvenil de estos protagonistas — jóvenes adolescentes — les hacía más ejemplares y modélicos: modelos de firmeza por la defensa de la fe.

Los dramaturgos y hagiógrafos del teatro jesuítico seguirán buscando modelos en jóvenes mártires de los primeros siglos del cristianismo para presentarlos como espejos en los que habían de mirarse los jóvenes estudiantes del Siglo de Oro por su fidelidad a la nueva religión y a la vez como modelos de castidad. Es el tema en el que se inspira el Diálogo de la gloriosa y bienaventurada virgen y mártir santa Cecilia y santos Tiburcio $y$ Valeriano $^{(36)}$. Es un caso de amor tratado de una manera muy singular. Los protagonistas son tres jóvenes patricios de la Roma Imperial: Valeriano, Tiburcio y Cecilia. La obra dramática comienza con un "romance» a la manera de prólogo donde se cuenta la historia.

Valeriano se enamora de Cecilia desconocedor de que la joven se ha convertido al cristianismo con voto de castidad. La joven no puede hacer público su compromiso religioso, pues estamos en plena persecución religiosa. El casamiento se realiza. Cuando los jóvenes se introducen en la cámara nupcial y Valeriano se dispone a consumar el matrimonio, Cecilia le cuenta su gran secreto; su amor ha de ser puramente espiritual; cualquier atrevimiento será castigado por el ángel que la acompaña el cual está presto a utilizar su espada para defender la fidelidad de la virgen con Cristo su esposo. Valeriano no ve en la habitación más que a su esposa; para ver al ángel - le dirá su esposa — es necesario que te bañes en las aguas sagradas que podrás encontrar en las catacumbas de los cristianos. Allá se dirige;

(36) Biblioteca Real de la Historia, Ms. 9/2568, fols. 144r-175v. 
se encuentra con el Papa quien le cuenta todo el proceso de conversión de Cecilia. Las aguas sagradas serán el bautismo que recibe de manos de Sumo Pontífice; vuelto a casa va al encuentro de su esposa que está en la alcoba; allí la encuentra efectivamente acompañada del ángel que les ciñe a ambos con dos coronas de guirnaldas de rosas. La fragancia de las rosas despierta la curiosidad de Tiburcio, hermano de Valerio, el cual le persuade para que deje la idolatría; de esta manera, los tres afrontarán el martirio. He aquí un argumento más sazonado de leyenda que de historicidad. No importa. Al dramaturgo le interesa recrear dramáticamente unos ejemplos que podían servir de modelos de castidad y de fortaleza, dos de las grandes virtudes del universo cristiano, frente al paganismo.

Una lectura propagandística muy semejante se desprende de la Vida de san Eustaquio. El protagonista y su familia pertenecen al estamento militar romano; una misteriosa aparición de Cristo al joven Eustaquio en una escena cinegética es el comienzo de su conversión; después de una larguísima cadena de aventuras con su mujer y sus hijos, que recuerda el esquema narrativo de la novela bizantina, terminarán aceptando el martirio antes que rendir culto a los dioses paganos. Eustaquio, su mujer y sus hijos son presentados aquí como una familia modélica de firmeza en la fe cristiana. La ambientación del mundo pagano que subyace en todas estas obras no es ajeno a otra preocupación que siempre embargó a los pedagogos jesuitas: el peligro de un excesivo fervor por la Antigüedad Clásica que podía conducir a una paganización; en las obras del P. Acevedo, primer dramaturgo del teatro jesuítico, está muy presente esta idea. Los jesuitas desde sus colegios fueron grandes impulsores de los studia humanitatis, pero a la vez sintieron la zozobra y advirtieron de los peligros de paganización a los que podría abocar un excesivo entusiasmo por los autores clásicos. La expurgación de Terencio es un caso claro. Desde el teatro los dramaturgos jesuitas defenderán la idea de que por encima de la bondad estética del mundo clásico está la bondad moral del universo cristiano. 


\subsection{El santo como modelo de la eficacia en la consecución de la gracia divina}

El P. Cigorondo, uno de los más fecundos literatos de la Compañía, como poeta y como dramaturgo, compuso, entre otras varias obras, una Comedia a la gloriosa Magdalena ${ }^{(37)}$ de "dos mil setecientos versos más o menos", como dirá al final. La historia la recogen los evangelios: María Magdalena vivió cautiva del Amor profano hasta que descubre a Cristo, Amor divino. La gracia divina transformó radicalmente la vida de aquella meretriz hasta convertirla en una santa. La doctrina sobre la justificación fue uno de los puntos de mayor disensión en Trento por su divergencia con los protestantes. El agrio problema "de auxiliis» que convulsionó la espiritualidad del Siglo de Oro está aquí presente según la tesis jesuítica del P. Molina. El dramaturgo desarrolla la obra tomando como núcleo dramático la lucha interior de estos dos impulsos antitéticos, que tomarían cuerpo existencial en aquellos jóvenes estudiantes. María Magdalena se convierte así en un modelo que supo vencer al amor profano. Una de las cuartetas finales es bien explícita:

$$
\begin{aligned}
& \text { Sírvaos María de exemplo } \\
& \text { en ver con la integridad, } \\
& \text { que en sintiendo la verdad } \\
& \text { supo fabricarle el templo (38). }
\end{aligned}
$$

\subsection{El santo como modelo de espíritu misionero}

La vocación misionera, finalidad primera de la Compañía, aparece muy temprano en el teatro jesuítico. La figura de san Francisco Javier, compañero de san Ignacio desde los inicios, partirá como misionero para la India

\footnotetext{
(37) Biblioteca Nacional, 17.286, fols. 13r-87v.

(38) Ibidem, fol. 87r.
} 
en 1540. Sus cartas misioneras dirigidas a los miembros de la orden, en las que contaba los avatares de su evangelización por tierras del lejano Oriente, fueron siempre punto de referencia espiritual para mantener viva la vocación de catolicidad con que nació la Compañía. La Gran Comedia de san Francisco Javier, el Sol en Oriente y el Coloquio de la conquista espiritual del Japón hecha para san Francisco Javier(39) (BRH, 9/2575) son dos hagiografías cuyas características estilísticas de una y otra obra remiten al barroco; las dos son anónimas y presentan al santo navarro como modelo de una catolicidad sin fronteras culturales, étnicas y políticas:

\author{
valeroso adalid contra el infierno, \\ luz de la compañía y ornamento, \\ apóstol que entre bárbaras naciones \\ dio luz donde no alcanzan los Triones ${ }^{(40)}$
}

\title{
A modo de conclusión
}

Los distintos santos que inspiran la comedia hagiográfica del teatro jesuítico son presentados como modelos, cuyo devenir existencial ejemplifica las nuevas orientaciones de la espiritualidad pergeñada por san Ignacio, quien a su vez asume las nuevas prerrogativas que dimanan del concilio de Trento. Contrarreforma y espiritualidad ignaciana, expresada literariamente de manera muy singular por el P. Alonso Rodríguez ${ }^{(41)}$ o el P. Ribadeneira, serían, a mi juicio, los soportes ideológicos que subyacen en el texto dramático, cuyas técnicas escénicas y dramáticas siguen los postulados del carácter docente de este teatro escolar. Como dirá Alonso Asenjo, "la Compañía de

(39) Biblioteca Real de la Historia, 9/2575.

(40) Biblioteca Real de la Historia, Ms. 9/2575, fol. 2v.

(41) Como ya se dijo, el P. ALONSO RODRÍGUEZ (1538-1616) es el autor del Ejercicio de perfección y virtudes cristianas, una de las obras que mayor impronta ha dejado no solo en la espiritualidad y ascesis de los miembros de la Compañía de Jesús, sino que trascendió a otras comunidades religiosas, por lo que se le considera un clásico de la espiritualidad de nuestro Siglo de Oro. 
Jesús centrará sus esfuerzos en la aceptación de la religiosidad católica activa y militante, en la ascética y en la teología»(42). La hagiografía del teatro 126 jesuítico es una manifestación más del arte al servicio de la propaganda ideológica generada por la Contrarreforma.

(42) Julio ALONSO ASENJO, La Tragedia de san Hermenegildo y otras obras del Teatro Escolar Español de Colegio, Sevilla-Valencia, UNED, 1995, Vol. I, p. 27 
(Página deixada propositadamente em branco) 


\section{Série}

\section{Documentos}

Imprensa da Universidade de Coimbra

Coimbra University Press

2006

- $\mathrm{U}$

C • 